\title{
Rewarding and Psychomotor Stimulant Effects of Endomorphin-1: Anteroposterior Differences within the Ventral Tegmental Area and Lack of Effect in Nucleus Accumbens
}

\author{
Abraham Zangen, ${ }^{1}$ Satoshi Ikemoto, ${ }^{1}$ James E. Zadina, ${ }^{2}$ and Roy A. Wise ${ }^{1}$ \\ ${ }^{1}$ National Institute on Drug Abuse, National Institutes of Health, Baltimore, Maryland 21224, and ${ }^{2}$ Veterans Affairs Medical \\ Center and Department of Medicine and Neuroscience Program, Tulane University School of Medicine, New Orleans, \\ Louisiana 70112
}

Endomorphin-1 (EM-1) is a recently isolated endogenous peptide having potent analgesic activity and high affinity and selectivity for the $\mu$-opioid receptor. The present study was designed to investigate the rewarding and psychomotor stimulant effects of EM-1 in specific brain regions. We found that rats would learn without priming or response shaping to lever-press for microinjections of EM-1 into the ventral tegmental area (VTA); responding was most vigorous for high-dose injections into the posterior VTA. Rats did not learn to lever-press for microinjections of EM-1 into the nucleus accumbens (NAS) or regions just dorsal to the VTA. Lever-pressing for EM-1 in the VTA was extinguished when vehicle was substituted for the peptide and was reinstated when EM-1 reinforcement was re-established. Conditioned place preference was established by EM-1 injections into the posterior but not the anterior VTA or the NAS. Injection of EM-1 (0.1-1.0 nmol) into the posterior VTA induced robust increases in locomotor activity, whereas injections into the anterior VTA had very weak locomotor-stimulating effects. When injected into the NAS, EM-1 $(0.1-10.0 \mathrm{nmol})$ did not affect locomotor activity. The present findings implicate the posterior VTA as a highly specific and sensitive site for opioid reward and suggest a role for EM-1-containing projections to the posterior VTA in the rewarding effects of other reinforcers.

Key words: endomorphin-1; reward; locomotion; ventral tegmental area; nucleus accumbens; intracranial self administration
Exogenous opiates are rewarding because they activate opioid receptors serving endogenous opioid transmission. The $\mu$-opioid receptor plays the primary role in opioid drug reward, with a smaller contribution of the $\delta$ receptor (Negus et al., 1993; Devine and Wise, 1994; Piepponen et al., 1997). Because opiate antagonists attenuate the impact of natural rewards (Brown and Holtzman, 1979; Kirkham and Cooper, 1988; Cooper and Turkish, 1989) as well as some nonopioid drug rewards (Corrigall and Coen, 1991; Navarro et al., 2001; Sinclair, 2001), and because these effects are observed with antagonists or doses that are relatively selective for the $\mu$ receptor, it seems likely that an endogenous ligand for the $\mu$-opioid receptor contributes to natural reward function. Among the various endogenous opioids, the recently identified peptide endomorphin-1 (EM-1) is the most selective for the $\mu$ receptor (Zadina et al., 1997).

Exogenous opioids are reported to have rewarding actions in several brain structures, the most clearly implicated of which are the ventral tegmental area (VTA) and the nucleus accumbens (NAS) (Wise, 1989). Rats will work for injections of opioids directly into the VTA (Bozarth and Wise, 1981; Welzl et al., 1989; Devine and Wise, 1994), and VTA injections of opioids can establish conditioned preferences for the places where the injections are experienced (Bals-Kubik et al., 1993; Nader and van der

Received March 26, 2002; revised May 29, 2002; accepted June 4, 2002.

This work was supported by the National Institute on Drug Abuse, Intramural Research Program. We thank Dr. M. Morales for her suggestions and technical assistance.

Correspondence should be addressed to Dr. Abraham Zangen, National Institute on Drug Abuse, National Institutes of Health, 5500 Nathan Shock Drive, Baltimore, MD 21224. E-mail: azangen@intra.nida.nih.gov.

Copyright (C) 2002 Society for Neuroscience $0270-6474 / 02 / 227225-09 \$ 15.00 / 0$
Kooy, 1997; Olmstead and Franklin, 1997). Rats will also work for injections of opioids into the NAS (Olds, 1982; Goeders et al., 1984), but there is some disagreement as to whether opioids in the NAS can establish conditioned place preference (Bals-Kubik et al., 1993; Olmstead and Franklin, 1997; Schildein et al., 1998). Thus, it is the VTA that is most clearly implicated in opiate reward.

The rewarding effects of opiate injections into the VTA are mediated by $\mu$ receptors expressed by GABA-containing cells in this region. Morphine and $\mu$ agonists inhibit the GABAergic cells, which, in turn, normally inhibit their mesolimbic dopaminergic neighbors (Johnson and North, 1992). The mesolimbic dopamine system is well established as a major component of the endogenous reward circuitry of the brain; activation of the mesolimbic neurons by opiates, by nicotine, or by electrical stimulation in the region of the medial forebrain bundle is rewarding, as is elevation of dopamine levels at the terminals of this system by amphetamine or cocaine (Wise et al., 1978; Wise, 1996; Ikemoto and Panksepp, 1999). Dopamine in the NAS is thought to be rewarding because it inhibits medium spiny neurons in this region, and the action of opiates in the NAS is also to inhibit medium spiny neurons (Carlezon and Wise, 1996).

Although there has been no such differentiation of the rewarding effectiveness of morphine in the VTA (Bozarth, 1987), studies of GABAergic agents suggest that the anterior and posterior VTA play very different roles in reward function. GABA agonists are rewarding in the posterior VTA, whereas GABA antagonists are rewarding in the anterior VTA (Ikemoto et al., 1997, 1998).

The present study was designed to explore the rewarding and locomotor-stimulant effects of the endogenous $\mu$ opioid EM- 1 in the VTA and NAS. Of particular interest were comparisons of 
injections in the anterior and posterior VTA; injections rostral, caudal, and dorsal to the VTA were also studied.

\section{MATERIALS AND METHODS}

Subjects. One hundred forty-six male Sprague Dawley rats (Charles River Laboratories, Raleigh, NC) were used for these experiments. The rats, weighing between 270 and $330 \mathrm{gm}$ at the time of surgery, were housed in pairs before and individually after surgery. They were maintained under a reversed $12 \mathrm{hr}$ light/dark cycle and tested in darkness during the dark phase. Laboratory rat chow and water were available ad libitum in their home cages. Animals used in this study were maintained in facilities accredited by the American Association for the Accreditation of Laboratory Animal Care. All experiments were conducted in accordance with the guidelines of the Institutional Care and Use Committee of the National Institute on Drug Abuse, National Institutes of Health.

Surgical procedures. Each rat received a unilateral implant under pentobarbital-chloral hydrate anesthesia (31 and $142 \mathrm{mg} / \mathrm{kg}$, respectively) with a 26 gauge guide cannula directed at the following locations: the posterior VTA $(n=35), 1.5 \mathrm{~mm}$ dorsal to the posterior VTA $(n=$ $5)$, the anterior VTA $(n=35), 1.5 \mathrm{~mm}$ dorsal to the anterior VTA $(n=$ $5)$, the posterior hypothalamus $(n=8)$, the NAS shell $(n=42)$, or the NAS core $(n=16)$. The cannulas were angled toward the midline at $6^{\circ}$ (VTA) to avoid penetration of the midsagittal sinus or at $16^{\circ}$ (NAS) to avoid penetration of the lateral ventricle. Cannulas were directed at the following stereotaxic coordinates (Paxinos and Watson, 1998) (in millimeters; where AP indicates anteroposterior and L indicates lateral, relative to the bregma, and $\mathrm{V}$ indicates ventral from the skull surface): anterior VTA: AP -5.0, L 0.6, V 8.0 (or 6.5 for the dorsal control group); posterior VTA: AP -6.2 , L $0.5, \mathrm{~V} 8.0$ (or 6.5 for the dorsal control group); posterior hypothalamus: AP -4.0 , L $0.6, \mathrm{~V} 8.0$; NAS shell: AP +1.8, L 1.0, V 6.8; and NAS core: AP +1.5, L 1.6, V 6.2. The obturator or the injection needle protruded $1 \mathrm{~mm}$ below the guide cannula. Each rat was implanted with a guide cannula in a single brain site, and separate groups of rats were prepared for either the locomotor activity experiments (total $n=49$ ), the intracranial self-administration experiments (total $n=65$ ), or the conditioned place preference experiments (total $n=32$ ). For the intracranial self-administration experiments, separate groups of rats were prepared for each of the tested EM-1 doses.

Drugs. EM-1 was obtained from AnaSpec Inc. (San Jose, CA). It was dissolved in artificial CSF (aCSF) consisting of (in $\mathrm{mM}$ ): $148 \mathrm{NaCl}, 2.7$ $\mathrm{KCl}, 1.2 \mathrm{CaCl}_{2}$, and $0.85 \mathrm{MgCl}_{2}$. The EM-1 doses used in the different behavioral paradigms were based on previous studies using morphine (Bozarth and Wise, 1981; Devine and Wise, 1994).

Intracranial self-administration. After $5 \mathrm{~d}$ of recovery from surgery, each rat was placed in an operant chamber equipped with two levers and a cue light just above one of the levers. Lever-presses on one lever ("active" lever) caused an intracranial injection of aCSF (75 nl) over a period of $6 \mathrm{sec}$ and illuminated a cue light just above the lever for $10 \mathrm{sec}$. Additional lever-presses during this $10 \mathrm{sec}$ period were counted but did not cause additional injection. Responses on the other lever ("inactive" lever) were counted but caused no injections and illuminated no cue light. The rats were trained for five or six sessions; sessions were separated by 45-72 hr. Sessions lasted for $3 \mathrm{hr}$ or until 50 infusions were taken within a session. In sessions 1 through 4, the rats of each group earned either 0 , 50,250 , or 500 pmol of EM-1, dissolved in the aCSF, for each lever-press. In session 5, the rats that previously received EM-1 now earned only vehicle (aCSF), and those that earned only vehicle in sessions 1-4 now earned 250 pmol per infusion of EM-1. In session 6 (where applicable), all groups earned $250 \mathrm{pmol}$ per infusion of EM-1. Infusions into the brain were made using a head-mounted micropump assembly (Ikemoto and Sharpe, 2001).

Conditioned place preference. The conditioned place preference test was performed in a three-compartment apparatus (MED Associates, St. Albans, VT) consisting of a narrow middle compartment that connected the two large side compartments. The two side compartments differed by floor type and by wall color. Previous tests confirmed that rats showed no significant preference for one of the two compartments. In the conditioning phase, the animal experienced the effects of intracranial EM-1 in one of the two end compartments on three occasions and experienced the effects of vehicle injections in the other end compartment on the intervening days. EM-1 $(1.0 \mathrm{nmol}$ in $0.5 \mu \mathrm{l}$ delivered over $60 \mathrm{sec})$ or vehicle microinjections were given to the animal in its home cage, and the animal was immediately placed into the appropriate compartment for $15 \mathrm{~min}$. The exposure to conditioning compartments was counterbalanced. Two days after the last conditioning session, each animal was tested for place preference; it was placed in the middle compartment with the barriers removed, and the times spent in each compartment were recorded over a $15 \mathrm{~min}$ period.

Locomotor activity. Locomotion and rearing were estimated from beam crossings in a $40 \times 40 \mathrm{~cm}$ open field (AccuScan Instruments, Columbus, $\mathrm{OH}$ ). Distance traveled was estimated from interruptions of 32 photobeam pairs separated by $2.5 \mathrm{~cm}$ and placed $3 \mathrm{~cm}$ above the floor. The rearing was detected from interruptions of 16 photo beams separated by $2.5 \mathrm{~cm}$ and placed $20 \mathrm{~cm}$ above the floor. After recovery from the surgery, rats were habituated to the test apparatus for six daily sessions (30 min each session), and then test days began. On each test day, each rat received an intracranial microinjection of $0.5 \mu \mathrm{l}$ of aCSF containing either $0,0.1,0.3$, or $1 \mathrm{nmol}$ of EM-1 delivered over a period of $60 \mathrm{sec}$ via a $10 \mu \mathrm{l}$ glass syringe. For injection of the $10 \mathrm{nmol}$ dose (only in the NAS groups), it was necessary to inject $1.0 \mu \mathrm{l}(120 \mathrm{sec})$ instead of $0.5 \mu \mathrm{l}(60$ $\mathrm{sec}$ ) because of the solubility limit of EM-1. The injector was left in place for an additional $30 \mathrm{sec}$, and then the rat was placed in the test apparatus. The order of EM-1 doses was counterbalanced. Each rat was tested for 30 min daily but was given drug injections only every other day; this was to minimize the development of conditioned locomotion.

Histology. After the experiments, the animals were killed by $\mathrm{CO}_{2}$ inhalation. A solution of Evans blue dye $(0.5 \mu \mathrm{l})$ was injected through the injection cannulas, and the brains were removed and soaked in $4 \%$ paraformaldehyde. Frozen coronal sections $30 \mu \mathrm{m}$ thick were stained with cresyl violet and examined microscopically. The exclusion criteria were based on the borders of the regions as determined by Paxinos and Watson (1998). Anterior versus posterior VTA placements were determined according to the existence (posterior) or no existence (anterior) of the interpeduncular nucleus just below the VTA in the coronal slice that included the tip of the injection cannula. Twelve brains from rats with anterior or posterior VTA cannula placements were processed for tyrosine hydroxylase $(\mathrm{TH})$ immunoreactivity for localization of target coordinates in relation to the dopamine cell bodies. These rats were anesthetized and perfused with $4 \%$ paraformaldehyde in $0.1 \mathrm{M}$ phosphate buffer (PB) solution. The brains were then removed from the skull, soaked in $4 \%$ paraformaldehyde $\left(2 \mathrm{hr}, 4^{\circ} \mathrm{C}\right)$, and transferred to a $15 \%$ sucrose solution. They were then frozen in dry ice and sliced into $30 \mu \mathrm{m}$ sagittal sections. Free-floating sections were incubated in $4 \%$ bovine serum albumin supplemented with $0.3 \%$ Triton X-100 in PB for $1 \mathrm{hr}$, followed by incubation with anti-TH mouse $\operatorname{IgG}(1: 250$, Boehringer Mannheim, Indianapolis, IN). After rinsing $3 \times 10 \mathrm{~min}$ in $\mathrm{PB}$, sections were processed with an ABC kit (Vector Laboratories, Burlingame, CA). Material was incubated in a 1:200 dilution of the biotinylated secondary antibody and then with avidin-biotinylated horseradish peroxidase. Samples were rinsed, and the peroxidase reaction was developed with $0.05 \%$ 3,3-diaminobenzidine- $4 \mathrm{HCl}$ and $0.003 \%$ hydrogen peroxide. The sections were mounted on coated slides, air dried, and examined under the microscope.

Statistical analysis. Data are expressed as the mean \pm SEM of values obtained from the indicated number of rats. Significance was determined by repeated ANOVA coupled with application of the Student-NewmanKeuls post hoc test as indicated. A $p$ value of $<0.05$ was considered significant.

\section{RESULTS}

\section{Intracranial self-administration}

Rats learned early within the first session to lever-press for EM-1 infusions into either the anterior or the posterior VTA (Figs. 1, 2). They also learned to distinguish between the reward-associated "active" and the reward-independent "inactive" levers (Figs. $1 C$, $2 C$ ). In contrast, rats did not learn to lever-press for EM-1 inf usions into the NAS shell (Fig. 3).

Animals receiving EM-1 injections into the posterior VTA lever-pressed significantly more than animals receiving EM-1 injections $1.5 \mathrm{~mm}$ dorsal to the posterior VTA and animals receiving vehicle injections into the posterior VTA. Moreover, a significant difference was found between groups receiving the 50 pmol per inf usion dose and the 250 pmol per infusion dose in the posterior VTA (Fig. 1A). When rats that received posterior VTA EM-1 in the first four sessions were exposed to vehicle (session 5), the infusion rate decreased significantly. Typically, the animals 
A

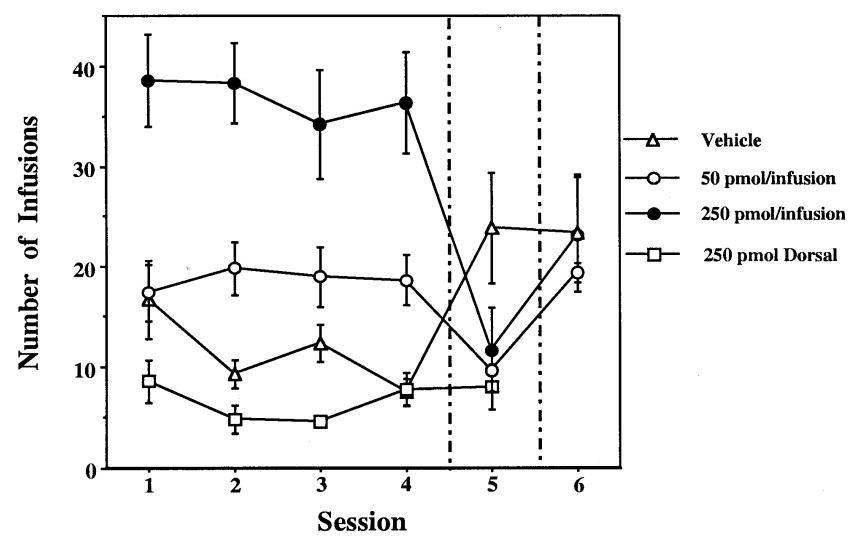

B

Time (min)

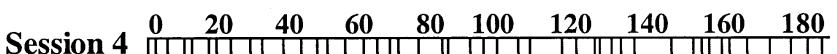

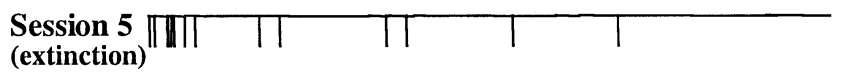

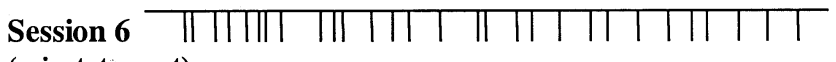
(reinstatement)

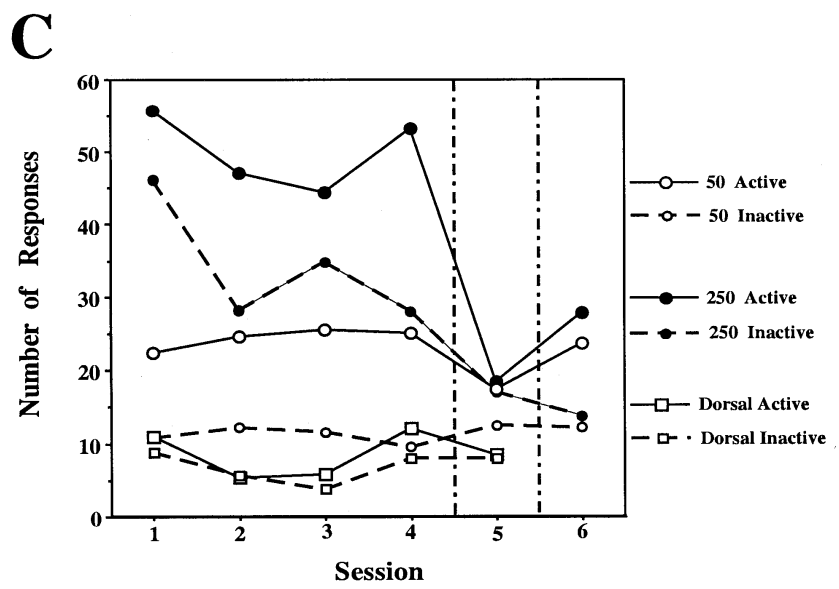

Figure 1. Self-administration of EM-1 into the posterior VTA. During the first four sessions, rats were allowed to press a lever for self-injection of aCSF containing either vehicle $(n=6)$ or 50 pmol per infusion $(n=5)$ or 250 pmol per infusion $(n=6)$ of EM-1 into the posterior VTA. Another group of rats was allowed to press a lever for self-injection of aCSF containing 250 pmol per infusion of EM-1 into a control site $1.5 \mathrm{~mm}$ dorsal to the posterior VTA $(n=5)$. In session 5 (separated by vertical lines), rats that previously received EM-1 were exposed to vehicle only, whereas rats that previously received vehicle now received 250 pmol per infusion of EM-1. In session 6, all groups received 250 pmol per inf usion of EM-1. $A$, Total number of infusions during each session for each group of rats. Repeated ANOVA over the first four sessions, comparing the three groups of rats receiving 0 or 50 or 250 pmol of EM- 1 per infusion into the posterior VTA, showed a significant effect of dose $\left(F_{(2,14)}=23.78 ; p<0.0001\right)$. Application of the Student-Newman-Keuls post hoc test revealed that both the 50 and 250 pmol doses were significantly different from vehicle $(0)$ and from each other. Repeated ANOVA over the first four sessions, comparing the group receiving 250 pmol per infusion into the posterior VTA and the group receiving $250 \mathrm{pmol}$ per infusion into the dorsal control site, showed a significant effect of site $\left(F_{(1,9)}=54.00 ; p<0.0001\right)$. A within-subject began responding normally but responded only sporadically after the first few minutes of the session (Fig. $1 B$ ). Normal responding resumed in session 6, when EM-1 reinforcement was re-established (Fig. $1 A, B$ ). Rats responded preferentially on the active lever rather than the inactive lever in the sessions in which EM-1 was available (Fig. 1C).

The groups responding for anterior VTA EM-1 responded significantly more often than the group receiving anterior VTA vehicle or the group that received EM-1 dorsal to the anterior VTA. However, no significant difference was found between groups receiving the $50 \mathrm{pmol}$ per infusion dose and the $250 \mathrm{pmol}$ per infusion dose in this case (Fig. $2 A$ ). Lever-pressing responses for EM-1 in the anterior VTA were extinguished during a session in which vehicle was substituted for the peptide (session 5) and reinstated when EM-1 reinforcement was re-established (session 6 ). The rats responded preferentially on the active lever rather than the inactive lever in the sessions in which EM-1 was available (Fig. 2C).

Animals responding for posterior VTA infusions of the high dose of EM-1 responded markedly more often than animals responding for anterior VTA infusions $\left(F_{(1,10)}=13.34 ; p=\right.$ $0.004)$. Moreover, animals responding for posterior VTA injections of the high dose of EM-1 responded more regularly than animals responding for the anterior VTA injections (Figs. $1 B$, $2 B$ ). The animals trained with the posterior VTA injections also showed faster and clearer extinction (session 5) (Figs. 1B, 2B).

Rats implanted with cannulas directed to the NAS shell did not learn to lever press for EM-1 inf usions. No significant differences were observed between the number of EM-1 infusions and the number of vehicle infusions, even when the dose of endomorphin was increased up to $500 \mathrm{pmol} / 75 \mathrm{nl}$ per infusion (which is close to the solubility limit). These rats did not learn to distinguish between the active and the inactive levers (Fig. 3).

\section{Locomotor activity}

EM-1 injections into the posterior VTA induced robust increases in locomotor activity. The effect was proportional to the dose over the range of $0.1-1.0 \mathrm{nmol}$ in $0.5 \mu \mathrm{l}$ injections (Fig. $4 A, C, D$ ). This was evident in both distance traveled $\left(F_{(3,27)}=6.94 ; p=0.001\right.$; $n=10)$ and the associated rearing scores $\left(F_{(3,27)}=5.07 ; p=\right.$ $0.006 ; n=10)$; post hoc analysis revealed that the locomotion induced by both the 0.3 and the $1.0 \mathrm{nmol}$ doses was significantly different from the locomotion induced by vehicle in the control condition. Conversely, when injected into the anterior part of the VTA, only the $1.0 \mathrm{nmol}$ dose of EM-1 induced some increase in locomotor activity (Fig. $4 B, C)\left(F_{(3,30)}=5.35 ; p=0.004 ; n=11\right)$.

\section{$\leftarrow$}

analysis over sessions 4-6 showed a significant effect of session for all three posterior VTA groups $\left(F_{(2,10)}=7.09, p=0.012 ; F_{(2,8)}=7.28, p=\right.$ $0.016 ; F_{(2,10)}=13.97, p=0.0013$ for the vehicle and 50 and 250 pmol doses, respectively). Application of the Student-Newman-Keuls post hoc test revealed that in all cases, the vehicle session was significantly different from the EM-1 sessions. $B$, Example of the infusion-rate pattern during sessions 4-6 of a rat with an injection cannula directed to the posterior VTA from the 250 pmol per infusion group. $C$, Comparison between the responses on the active versus the inactive lever during each session for each group of rats. Repeated ANOVA over the first four sessions comparing active versus inactive lever responses (within-subjects analysis) revealed that in both the $50 \mathrm{pmol}$ and $250 \mathrm{pmol}$ posterior VTA groups, active responses were significantly different from inactive responses $\left(F_{(1,4)}=63.85, p=0.0013\right.$, and $F_{(1,4)}=7.84, p=0.038$, respectively $)$, whereas no significant difference between active and inactive responses was observed in the dorsal control group $\left(F_{(1,4)}=3.20 ; p=0.14\right)$. 
A

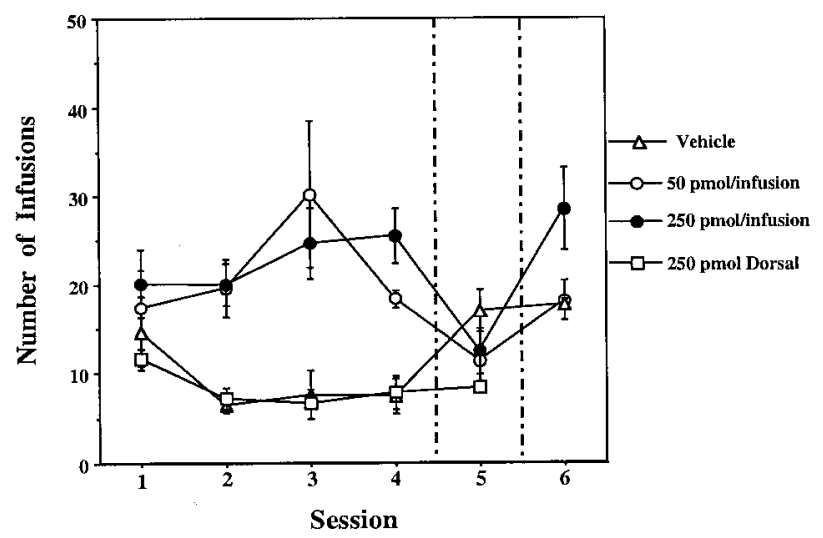

B

\begin{tabular}{|c|c|c|c|c|c|c|}
\hline & & & & Time (min) & & \\
\hline & 0 & 20 & 40 & $\begin{array}{lll}60 & 80 & 100\end{array}$ & $120 \quad 140$ & 160 \\
\hline
\end{tabular}
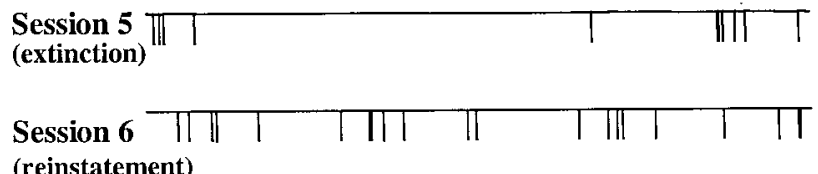
(reinstatement)

C

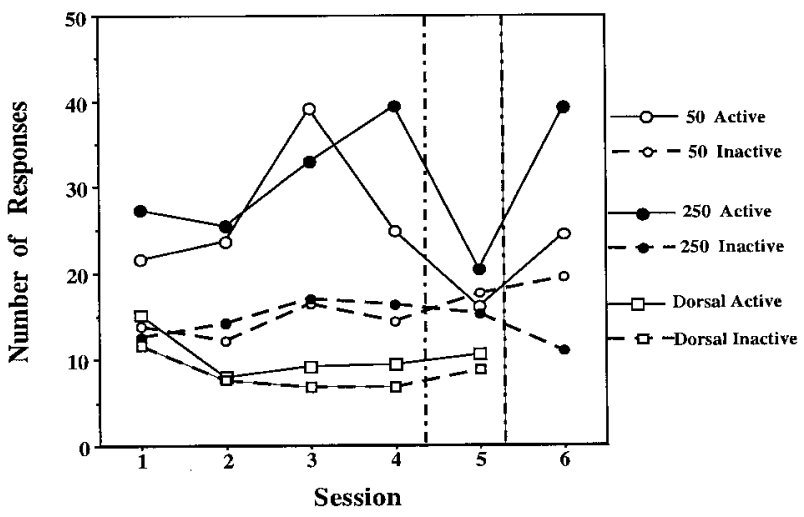

Figure 2. Self-administration of EM-1 into the anterior VTA. During the first four sessions, rats were allowed to press a lever for self-injection of aCSF containing either vehicle $(n=5)$ or 50 pmol per infusion $(n=5)$ or 250 pmol per infusion $(n=6)$ of EM-1 into the anterior VTA. Another group of rats was allowed to press a lever for self-injection of aCSF containing 250 pmol per infusion of EM-1 into a control site $1.5 \mathrm{~mm}$ dorsal to the anterior VTA $(n=5)$. In session 5 (separated by vertical lines), rats that previously received EM-1 were exposed to vehicle only, whereas rats that previously received vehicle now received 250 pmol per infusion of EM-1. In session 6, all groups received 250 pmol per inf usion of EM-1. A, Total number of infusions during each session for each group of rats. Repeated ANOVA over the first four sessions comparing the three groups of rats receiving 0 or 50 or 250 pmol of EM-1 per inf usion into the anterior VTA showed a significant effect of dose $\left(F_{(2,13)}=11.66 ; p=0.0013\right)$. Application of the Student-Newman-Keuls post hoc test revealed that both the 50 and 250 pmol doses were significantly different from vehicle (0) but not from each other. Repeated ANOVA over the first four sessions comparing the group receiving $250 \mathrm{pmol}$ per infusion into the anterior VTA and the group receiving $250 \mathrm{pmol}$ per infusion into the dorsal control site showed a significant effect of site $\left(F_{(1,9)}=101.66 ; p<0.0001\right)$. A withinsubjects analysis over sessions $4-6$ showed a significant effect of session for
No such increase was observed in the rearing scores (Fig. 4D) $\left(F_{(3,30)}=0.017 ; p>0.05 ; n=11\right)$. The effect of EM-1 injections into the anterior VTA on photo cell crossings was observed only after 10-15 min, whereas the effect of posterior VTA injections was not only higher but also evident from the first 5 min (Fig. $4 A, B)$. Injections of EM-1 $(0.1-1.0 \mathrm{nmol} / 0.5 \mu \mathrm{l})$ into the posterior hypothalamus, $1 \mathrm{~mm}$ rostral to the anterior VTA injection site, had no effect on locomotion or rearing (Fig. 4C,D).

Microinjections of EM-1 into the NAS shell or core did not significantly affect locomotion or rearing, even when the dose was increased up to $10.0 \mathrm{nmol}$ (shell: $F_{(4,44)}=2.44, p=0.061, n=12$; core: $\left.F_{(4,28)}=1.18, p=0.34, n=8\right)$ (Fig. 5). However, when amphetamine $(20 \mathrm{nmol} / 0.5 \mu \mathrm{l})$ was injected into the NAS shell or core of the same rats, the locomotor activity was significantly elevated $\left(\right.$ shell: $F_{(5,55)}=25.08, p<0.0001, n=12$; core: $F_{(5,35)}=$ $7.04, p=0.001, n=8)$. The magnitude of the effect of amphetamine $(20 \mathrm{nmol})$ injections into the NAS on locomotor activity was similar to that of the effect of EM-1 $(1.0 \mathrm{nmol})$ injections into the posterior VTA (Figs. 4, 5).

\section{Conditioned place preference}

The ability of EM-1 to produce conditioned place preference was tested by microinjections of either EM-1 (1 nmol) or vehicle into either the anterior or the posterior VTA or into the NAS shell or core. Because the effect of EM-1 microinjection on locomotor activity suggested that EM-1 may diff use from the anterior to the posterior VTA and produce some effect after 10-15 min, each conditioning session was limited to $15 \mathrm{~min}$ after the injection. Microinjections into the posterior VTA produced a significant preference for the EM-1-associated compartment $\left(t_{7}=3.83 ; p=\right.$ $0.006 ; n=8$; paired $t$ test), whereas microinjections of EM-1 into the anterior VTA did not $\left(t_{7}=0.69 ; p=0.51 ; n=8\right)$. EM-1 microinjections into either the shell or the core of the NAS failed to establish conditioned place preference $\left(t_{7}=1.47, p=0.18\right.$, and $t_{7}=1.09, p=0.31$, respectively; $n=8$ ) (Fig. 6).

\section{Placement of posterior and anterior VTA injections in relation to the boundaries of the dopamine cell group}

Both posterior and anterior VTA placements were within the boundaries of the cell group that was immunoreactive to $\mathrm{TH}$ antibody. The anterior placements were $0.2-0.5 \mathrm{~mm}$ anterior and the posterior placements were $0.4-0.7 \mathrm{~mm}$ posterior to the middle of the dopaminergic cell group (Fig. 7).

\section{DISCUSSION}

The endogenous $\mu$-opioid peptide EM-1 was self-administered into the anterior and the posterior VTA but not into the NAS and established conditioned place preference only when injected into

$\leftarrow$

all three anterior VTA groups $\left(F_{(2,8)}=27.68, p=0.0003 ; F_{(2,8)}=4.89\right.$ $p=0.041 ; F_{(2,10)}=9.88, p=0.0043$ for the vehicle and 50 and $250 \mathrm{pmol}$ doses, respectively). Application of the Student-Newman-Keuls post hoc test revealed that in all cases, the vehicle session was significantly different from the EM-1 sessions. $B$, Example of the infusion rate pattern during sessions 4-6 of a rat with an injection cannula directed to the anterior VTA from the 250 pmol per inf usion group. $C$, Comparison between the responses on the active versus the inactive lever during each session for each group of rats. Repeated ANOVA over the first four sessions comparing active versus inactive lever responses (within-subjects analysis) revealed that in both the $50 \mathrm{pmol}$ and $250 \mathrm{pmol}$ posterior VTA groups, active responses were significantly different from inactive responses $\left(F_{(1,4)}=14.30, p=0.019\right.$ and $F_{(1,4)}=11.62, p=0.019$, respectively $)$, whereas no significant differences between active and inactive responses were observed in the dorsal control group. 
A

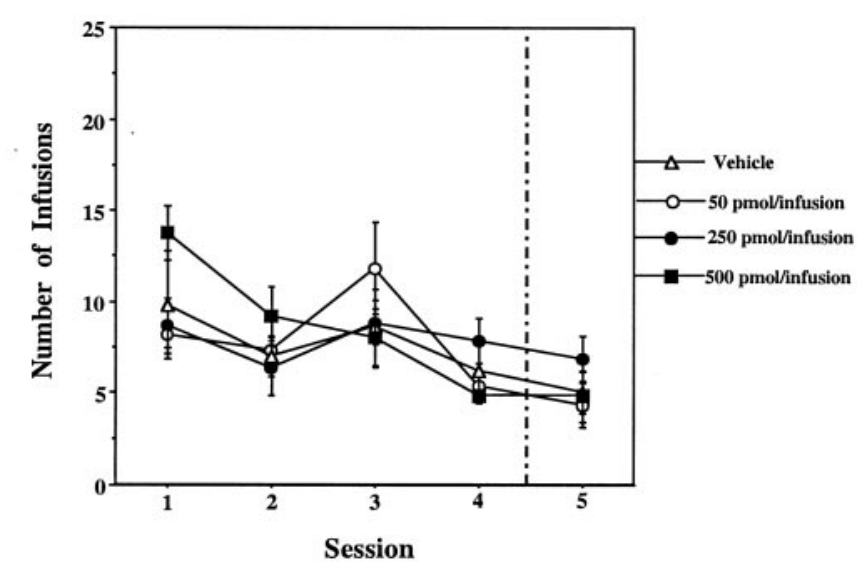

B

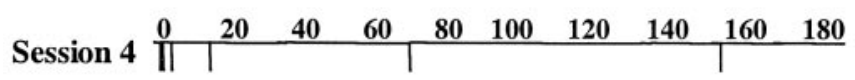
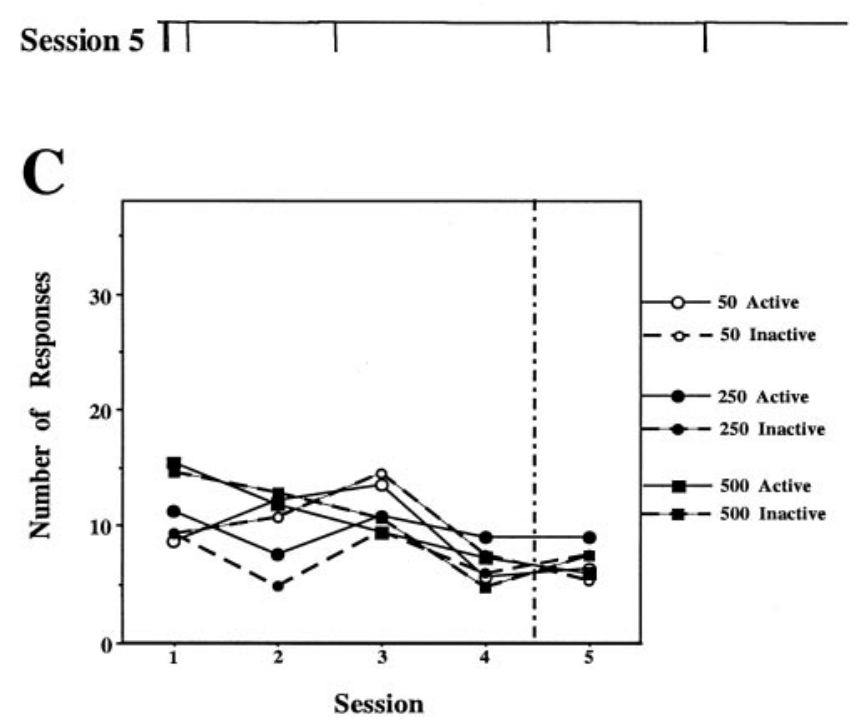

Figure 3. Self-administration of EM-1 into the NAS shell. During the first four sessions, rats were allowed to press a lever for self-injection of aCSF containing either vehicle $(n=5)$ or 50 pmol per infusion $(n=6)$, 250 pmol per infusion $(n=6)$, or 500 pmol per infusion $(n=5)$ of EM-1 into the NAS shell. In session 5 (separated by a vertical line), rats that previously received EM-1 were exposed to vehicle only, whereas rats that previously received vehicle now received 250 pmol per inf usion of EM-1. $A$, Total number of infusions during each session for each group of rats. Repeated ANOVA over the first four sessions comparing the four groups of rats receiving 0 or 50 or 250 or 500 pmol of EM-1 per inf usion into the NAS shell showed no significant effect of dose $\left(F_{(3,18)}=0.32 ; p=0.81\right)$. A within-subjects analysis comparing sessions 4 and 5 showed no significant effect of session in any of the NAS shell groups. B, Example of the infusion rate pattern during sessions 4 and 5 of a rat with an injection cannula directed to the NAS shell from the 250 pmol per infusion group. $C$, Comparison between the responses on the active versus the inactive lever during each session for each group of rats. Repeated ANOVA over the first four sessions comparing active versus inactive lever responses (within-subjects analysis) revealed no significant differences between active and inactive lever responses in any of the NAS groups. the posterior VTA. EM-1 also produced psychomotor stimulating effects when injected into the VTA but not when injected into the NAS. The psychomotor stimulant effects of EM-1 injections in the posterior VTA were stronger than those of injections in the anterior VTA. First, the lower doses of EM-1 caused locomotion only when injected into the posterior VTA. Second, the higher dose of EM-1 increased locomotion by $213 \%$ when injected into the posterior VTA but increased locomotion only by $26 \%$ when injected into the anterior VTA. Finally, the posterior VTA injections were effective within the first $5 \mathrm{~min}$, whereas the anterior VTA injections increased locomotion with a 10-15 $\mathrm{min}$ latency. The shorter latency suggests that the posterior injections were closer to their relevant site of action.

Posterior VTA injections of EM-1 also appear to have stronger rewarding effects in the self-administration paradigm. Although both the anterior and posterior VTA supported self-administration of EM-1, the higher dose of EM-1 was self-administered most frequently and regularly into the posterior VTA. The first question of importance is whether the increased lever-pressing caused by these earned injections reflected the fact that the injections were given only if the animal pressed the active lever or, alternatively, if they reflected nonspecific activating effects of accidentally earned injections. Several findings confirm that the injections were reinforcing and not just activating. First and most critical, the animals activated the active levers more than the duplicate inactive levers. Discrimination between the active and inactive levers is not always established so quickly and clearly indicates that the injections were reinforcing. The increased responding on the inactive lever in the high-dose posterior group (Fig. $1 C$ ) raises the possibility that the lever-pressing scores reflected many accidental lever counts, counts resulting from general activation rather than from the response contingency. The two-lever control condition does not offer any way to discriminate between stimulus generalization inactive lever counts and drug-induced activity of the animal. Stimulus generalization is the well known phenomenon of responding to a variety of stimuli in proportion to their similarity to the training stimulus. In the present case, the levers were identical and were centered in identical side walls of the testing apparatus, offering the greatest possible opportunity for generalization. The paradigm that separates reinforced lever-pressing from accidental or arousal-induced lever counts is a yoked paradigm in which the control animal has an inactive lever but no active lever but receives injections concurrently with an experimental animal that has an active but no inactive lever. Here, the control animal is never reinforced for pressing its inactive lever, and it is never reinforced for pressing an identical lever on the opposite wall. When the yoked paradigm has been used in studies of intracranial opiate self-administration into the VTA, no inactive lever-responding has been seen, despite vigorous drug-induced locomotion (Bozarth and Wise, 1981; Devine and Wise, 1994).

A second finding confirming that EM-1 injections in the posterior VTA were reinforcing and not just activating is the conditioned place preference established by these injections, because drug-induced locomotion is not correlated with conditioned place preference scores. Although drug-induced locomotion can artificially elevate place preference scores in an unbalanced paradigm (Bozarth, 1987), the present paradigm was a balanced paradigm. Given that naive rats (without conditioning) spend equal time in the two compartments, drug-induced locomotion would not bias the scores of the present test. First, the animals are tested in the drug-free condition, so drug-induced locomotion is not relevant to the scores on the test day. Second, although the association 
A

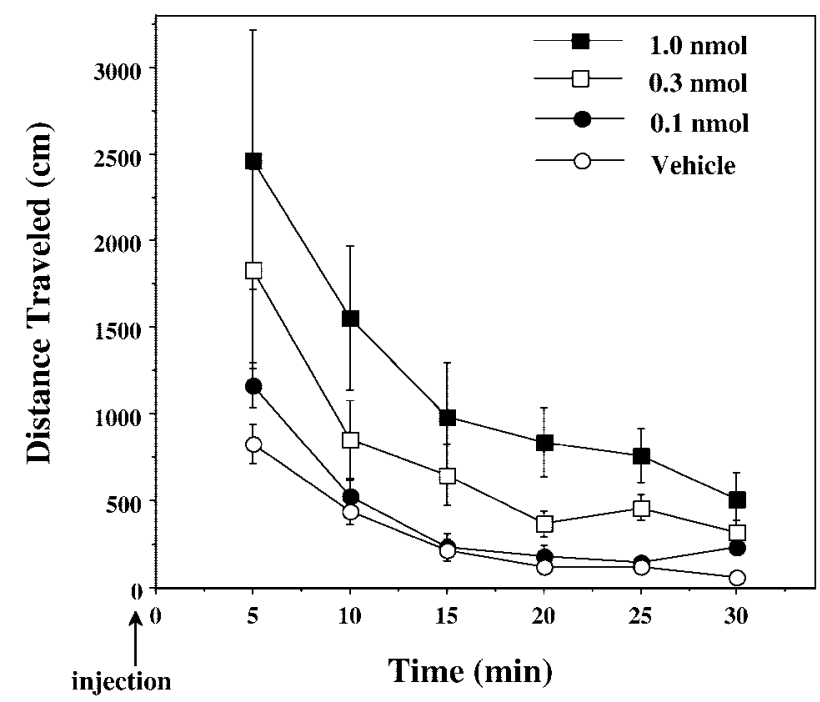

C

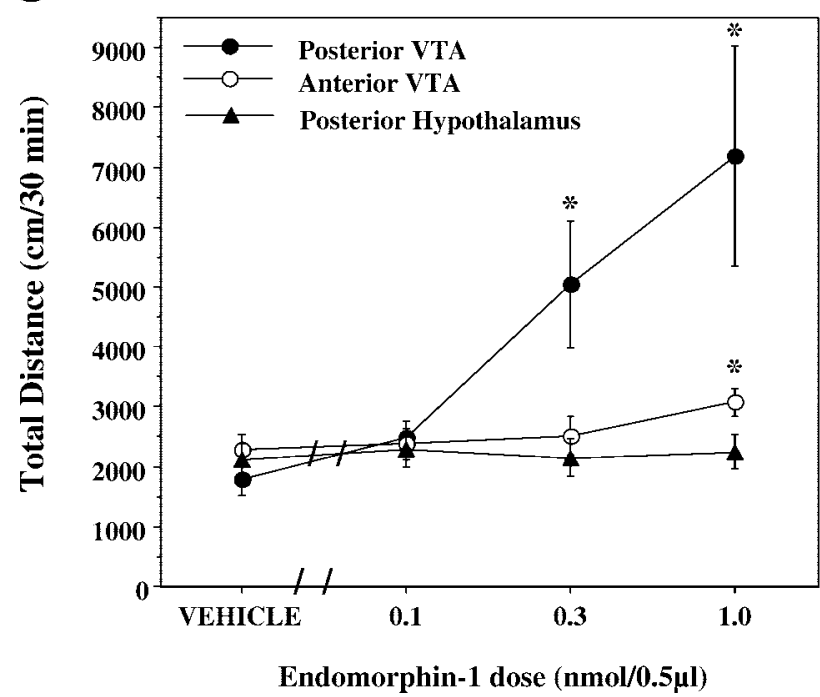

B

Anterior VTA

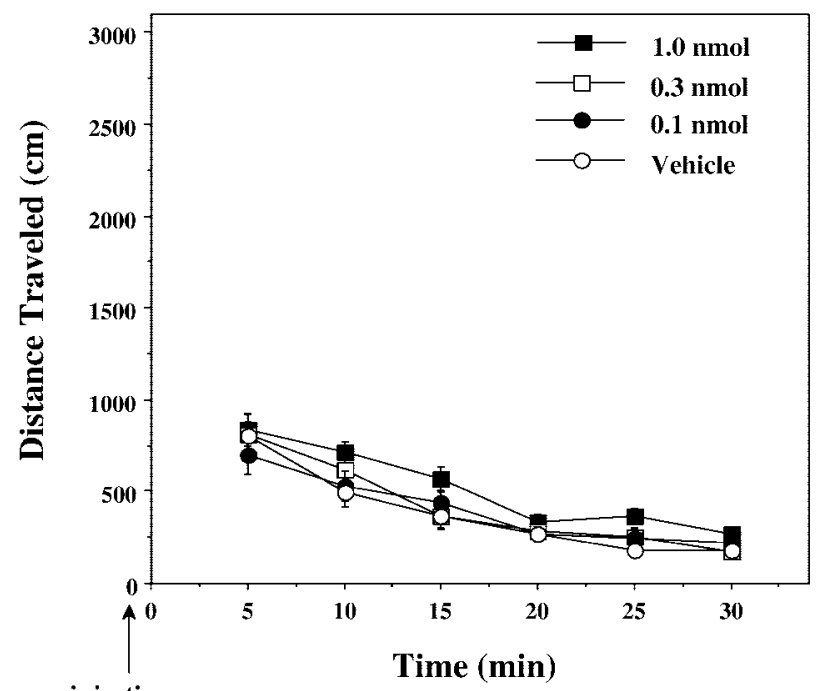

injection
D

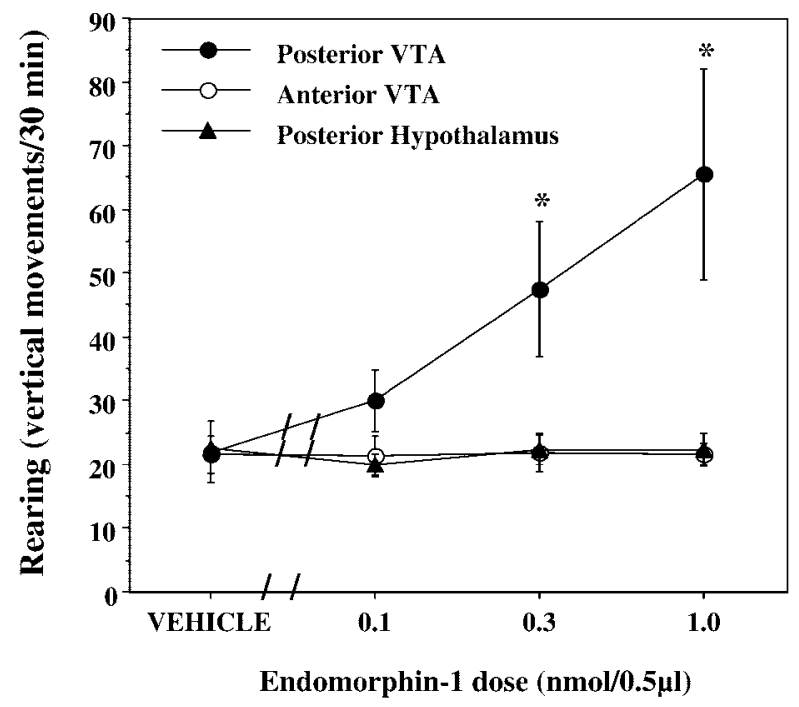

Figure 4. Effect of EM-1 microinjections into the posterior hypothalamus or anterior or posterior VTA on locomotor activity. $A$, $B$, Time course of the distance traveled during $30 \mathrm{~min}$ sessions after EM-1 $(0-1.0 \mathrm{nmol} / 0.5 \mu \mathrm{l})$ injections into the posterior and anterior VTA, respectively. $C$, $D$, Dose-response effects of EM-1 microinjections into the posterior hypothalamus $(n=8)$ or anterior $(n=11)$ or posterior $(n=10)$ VTA on the total distance and the rearing activity during the entire session. Data are presented as means \pm SEM. Data were analyzed by one-way ANOVA with repeated measures over the four doses, coupled with application of the Student-Newman-Keuls post hoc test. * $p<0.01$ versus effect of the vehicle microinjections.

between drug and one side of the apparatus may cause conditioned locomotion when the animal is on that side of the apparatus, conditioned locomotion would serve only to increase the probability that the animal would leave the drug-associated side. The lack of conditioned locomotion on the vehicle-associated side would reduce the probability of locomotion on that side and thus reduce the probability of moving to the drug-associated side. Moreover, stronger conditioned place preferences are established by sedative doses of opiates than by locomotor-stimulating doses of opiates (Bozarth, 1987; van der Kooy, 1987); similarly, stronger conditioned place preferences are established by stereotypyinducing doses than by locomotor-inducing doses of amphetamine and cocaine (Bardo et al., 1999).
Although responding was greater for the high-dose injections into the posterior VTA, responding for the low-dose injections into the posterior VTA was no greater than responding for the low dose into the anterior VTA. This is a problematic finding, because the simplest explanation of the high-dose differences would be that the posterior VTA is the site of rewarding action and that the injections into the anterior VTA were less effective because they were delayed and diluted by the time they diff used to the posterior site. If the high-dose injections in the anterior VTA were less reinforcing than the high-dose injections in the posterior VTA, why were the low-dose anterior injections equally effective to the low-dose posterior injections? Similarly, why were the low- and high-dose anterior injections equally effective? The 
A

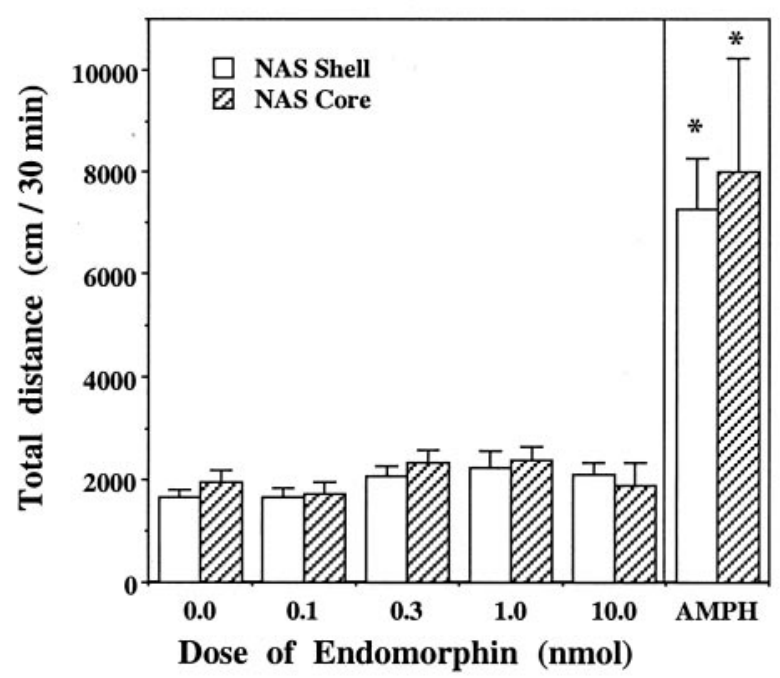

B

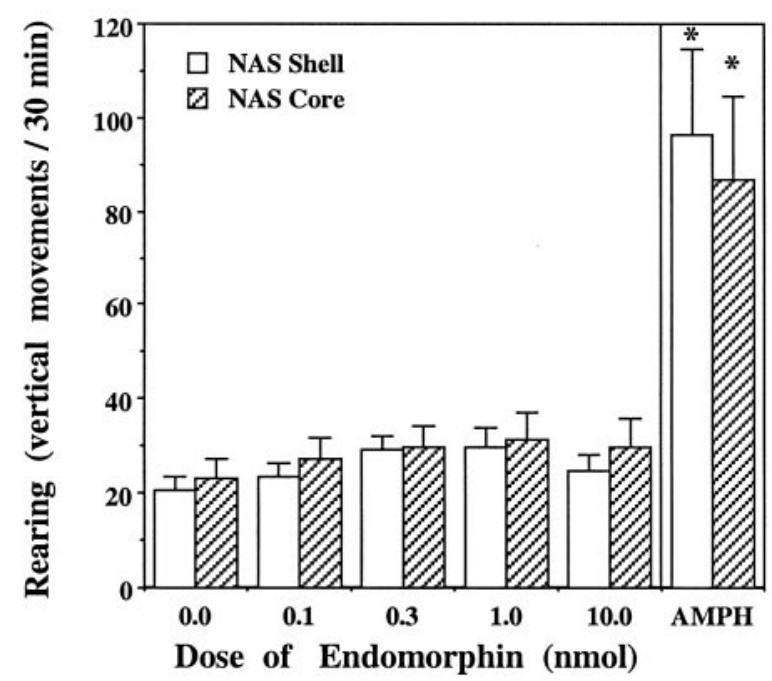

Figure 5. Effect of EM-1 and amphetamine $(A M P H)$ microinjections into the NAS shell or core on locomotor activity. Data are presented as means \pm SEM values of the total distance $(A)$ and the total rearing activity $(B)$ measured during $30 \mathrm{~min}$ sessions after EM-1 $(0-10.0 \mathrm{nmol})$ or amphetamine $(20.0 \mathrm{nmol})$ injections into the NAS shell $(n=12)$ or core $(n=8)$. One-way ANOVA with repeated measures over the five EM-1 doses showed no significant effect of the EM-1 dose (shell: $F_{(4,44)}=2.44$, $p=0.061$; core: $\left.F_{(4,28)}=1.18, p=0.34\right)$. However, when the amphetamine session was included in the repeated ANOVA, a significant effect of session was obtained (shell: $F_{(5,55)}=25.08, p<0.0001$; core: $F_{(5,35)}=$ $7.04, p<0.001)$. An asterisk indicates a significant difference from vehicle treatment (by application of the Newman-Keuls post hoc test).

only explanation we can offer for this question comes from the pattern of the responses in all these groups. Animals in both anterior groups and in the low-dose posterior group tended to respond in "bursts," suggesting that several infusions grouped together were required for the same effectiveness as a single injection in the high-dose posterior group. Responding in the posterior high-dose group was more regular and suggests a more immediate rewarding effect. A delayed rewarding effect in all

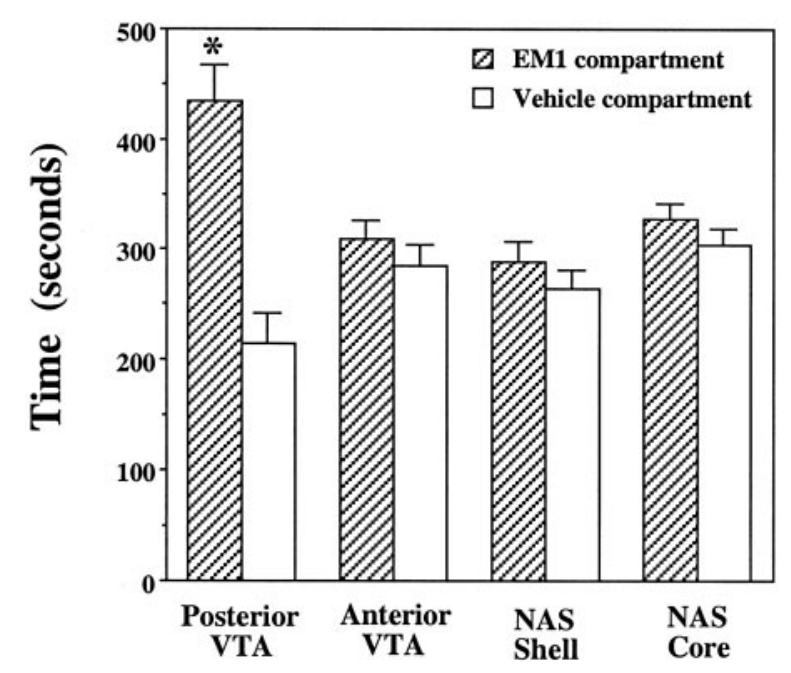

Figure 6. Conditioned place preference induced by intracranial microinjections of EM-1. Data are presented as mean \pm SEM values of the total time spent in the EM-1-associated and the vehicle-associated compartments during the 15 min test session $\left(n=8\right.$ for each brain site; ${ }^{*} p<0.05$; paired $t$ test).

other groups may limit the maximal reinforcement that can be established.

The most convincing finding indicating that EM-1 is rewarding in the posterior VTA rather than in the anterior VTA is the fact

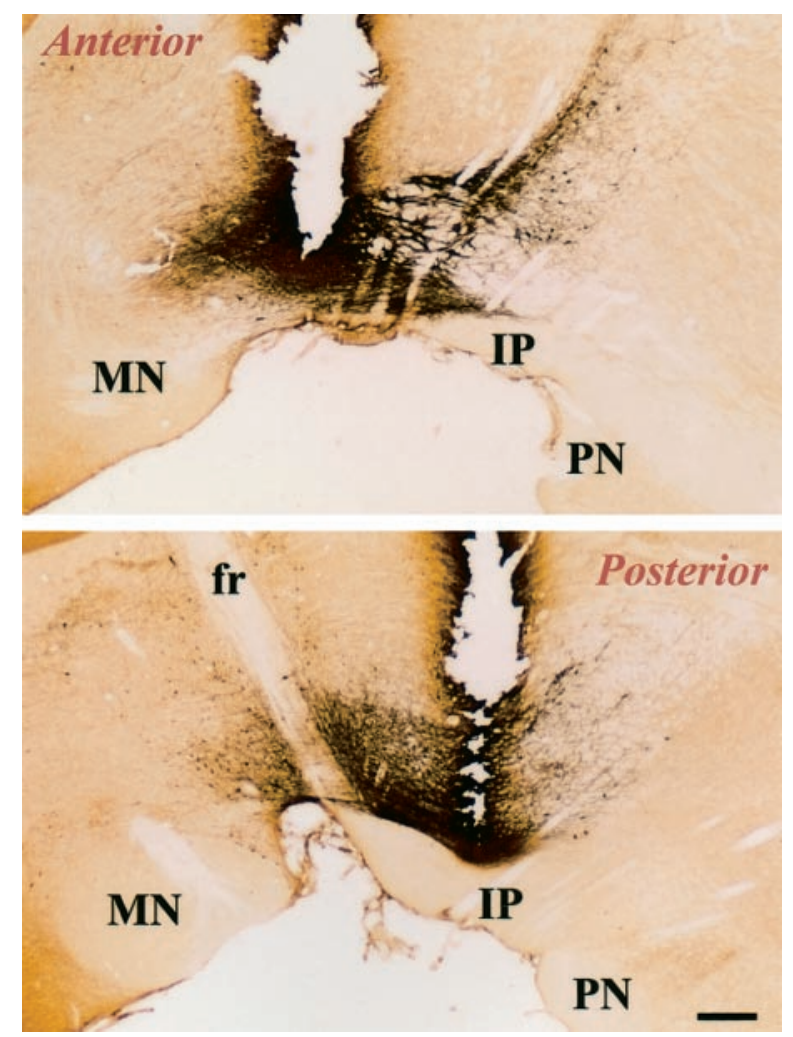

Figure 7. Placement of posterior and anterior VTA injections as related to the boundaries of dopamine cell bodies. Photomicrographs show sagittal sections through the VTA, with the track of the injection needle (top, anterior site; bottom, posterior site). The sections were immunostained for $\mathrm{TH}$, showing the boundaries of the dopaminergic cells of the VTA. IP, Interpeduncular nucleus; $P N$, paranigral nucleus; $M N$, mamillary nucleus; $\mathrm{fr}$, fasciculus retroflexus. Scale bar, $0.35 \mathrm{~mm}$. 
that EM-1 established conditioned place preference only when injected into the posterior VTA. The unequivocal data from the place preference test, coupled with the fact that the posterior VTA injections were more effective at inducing the locomotion that is a well known correlate of VTA opiate reward (Bozarth and Wise, 1981; Devine and Wise, 1994) and, indeed, reward in general (Glickman and Schiff, 1967; Wise and Bozarth, 1987), suggest strongly that opiate reward sites in the VTA are concentrated in the posterior region of this dopamine cell group.

Bozarth (1987) failed to detect anteroposterior differences in the ability of VTA morphine injections to establish conditioned place preferences. Possible explanations of his failure to find differences similar to those revealed in the present study are that he used relatively high doses of morphine and conditioning sessions that were twice as long as those used in the present study. High doses would spread further and thus offer a less sensitive index of anatomic localization. The most likely explanation of the discrepancies between the present study and the Bozarth study is that there was greater spread of drug from the anterior to the posterior VTA in the Bozarth study. The most critical factor may have been the length of the sessions; in the Bozarth study, morphine had greater time to diffuse. Presumably, the most salient memory of the rat is for the last minutes in the conditioned place preference apparatus; thus, lower doses and shorter duration of conditioning seem likely to offer the more sensitive test of subtle localization of the effects of microinjected drug. Moreover, the endogenous peptide may spread less than morphine because it is rapidly degraded by peptidases (Peter et al., 1999). The fact that EM-1 injections established conditioned place preferences only when injected into the reasonably restricted area of the posterior VTA explains the previous finding (Wilson et al., 2000) that intracerebroventricular injections of EM-1 are not rewarding; injections into the lateral ventricle would diffuse to the posterior VTA even less readily than our relatively ineffective EM-1 injections into the anterior VTA.

The idea that the VTA is not functionally homogeneous with respect to locomotor and reward function first arose from studies of GABAergic agonists and antagonists. Arnt and Scheel-Krüger (1979) found that the GABA $_{A}$ agonist muscimol stimulated locomotion when injected into the caudal VTA; this effect was blocked by the $\mathrm{GABA}_{\mathrm{A}}$ antagonist picrotoxin and prevented by dopamine depletion. When it was injected into the anterior VTA, however, opposite effects were seen: picrotoxin stimulated locomotion and muscimol inhibited it. In parallel with the locomotion findings, muscimol is self-administered into the posterior VTA (and this is antagonized by picrotoxin), whereas picrotoxin is self-administered into the anterior VTA (antagonized by muscimol) (Ikemoto et al., 1997, 1998). It is possible that a common mechanism underlies the anteroposterior differences observed with GABAergic agents and EM-1; however, it is also possible that the anteroposterior differences observed with EM-1 relate merely to the density of $\mu$-opioid receptors. Indeed, examination of the immunohistochemical localization of the cloned $\mu$-opioid receptor in sagittal slices through the VTA suggests a higher density of $\mu$-opioid receptors in the posterior than the anterior VTA (Mansour et al., 1995). An additional line of evidence implicating functional heterogeneity of the VTA is that overexpression of the AMPA receptor subunit in the anterior VTA enhances the rewarding effects of systemic morphine, whereas overexpression in the posterior VTA establishes aversive effects of systemic morphine (Carlezon et al., 2000). The present study extends the generality of the conclusion that there are anteropos- terior differences in the motivational functions of the VTA and implicates the posterior portion of the VTA in opioid reward.

It was not entirely surprising that EM-1 was not rewarding in the NAS. The effects of opioid injections into the NAS are generally less robust than their effects in the VTA. There are several failures to demonstrate opioid-conditioned place preference or intracranial self-administration with injections into NAS (Bozarth and Wise, 1982; Bals-Kubik et al., 1993; Olmstead and Franklin, 1997; Schildein et al., 1998). Moreover, in cases in which the stimulant- or reward-associated effects of opioid microinjections into the VTA have been compared with the effects of similar doses of the same agents into the NAS, the drugs have been at least an order of magnitude more potent in the VTA (Kalivas et al., 1983; Jenck et al., 1987). Although bilateral microinjections of the $\mu$ agonist $\left[\mathrm{D}-\mathrm{Ala}^{2}-\mathrm{N}-\mathrm{Me}-\mathrm{Phe}^{4}-\mathrm{Glycol}^{5}\right.$ ]-enkephalin (DAMGO) into the NAS can induce locomotion (Kalivas et al., 1983; Johnson et al., 1996; Churchill et al., 1998), it is only after chronic suppression of dopamine function (Stinus et al., 1985; Churchill and Kalivas, 1992) that NAS opioid injections have potent psychomotor stimulant effects. Interestingly, the locomotor stimulating effect of DAMGO in the NAS is not only weak but also generally delayed. Latencies are in the range of 30-120 min after microinjection into the NAS (Johnson et al., 1996; Churchill et al., 1998); this long latency raises the possibility of diffusion to a distant site of action and may also explain the lack of EM-1 effect, because EM-1 is rapidly inactivated (Peter et al., 1999). Moreover, Hoffman and Lupica (2001) have reported that medium spiny neurons of the NAS are inhibited by a mixed $\mu$ and $\delta$ agonist but are not affected by DAMGO, a selective $\mu$ agonist. Morphine, which was reported to be self-administered into the NAS (Olds, 1982), has mixed $\mu$ and $\delta$ actions, whereas the EM- 1 used in the present study, like DAMGO in the Hoffman and Lupica (2001) study, is highly selective for $\mu$ receptors.

The fact that opiate antagonists attenuate responding for food, water (Brown and Holtzman, 1979), and sucrose reward (Kirkham and Cooper, 1988; Cooper and Turkish, 1989) and for several nonopioid drugs of abuse (Corrigall and Coen, 1991; Navarro et al., 2001; Sinclair, 2001) indicates a role for endogenous opioids in brain reward circuitry. EM-1 afferents to the posterior VTA (Martin-Schild et al., 1999) are a possible substrate of these effects. Two EM-1-containing cell groups have been described in the brain: one in the hypothalamus and one in the nucleus of the solitary tract (Martin-Schild et al., 1999); the present data suggest that the cells projecting to the posterior portion of the VTA from one of these two groups make an important endogenous opioid contribution to motivational function.

\section{REFERENCES}

Arnt J, Scheel-Krüger J (1979) GABA in the ventral tegmental area: differential regional effects on locomotion, aggression and food intake after microinjection of GABA agonists and antagonists. Life Sci 25:1351-1360.

Bals-Kubik R, Ableitner A, Herz A, Shippenberg TS (1993) Neuroanatomical sites mediating the motivational effects of opioids as mapped by the conditioned place preference paradigm in rats. J Pharmacol Exp Ther 264:489-495.

Bardo MT, Valone JM, Bevins RA (1999) Locomotion and conditioned place preference produced by acute intravenous amphetamine: role of dopamine receptors and individual differences in amphetamine selfadministration. Psychopharmacology 143:39-46.

Bozarth MA (1987) Neuroanatomical boundaries of the reward-relevant opiate-receptor field in the ventral tegmental area as mapped by the conditioned place preference method in rats. Brain Res 414:77-84.

Bozarth MA, Wise RA (1981) Intracranial self-administration of morphine into the ventral tegmental area in rats. Life Sci 28:551-555. 
Bozarth MA, Wise RA (1982) Localization of the reward-relevant opiate receptors. In: Problems of drug dependence 1981 (Harris LS, ed), pp 158-164. Washington, DC: U.S. Government Printing Office.

Brown DR, Holtzman SG (1979) Suppression of deprivation-induced food and water intake in rats and mice by naloxone. Pharmacol Biochem Behav 11:567-573.

Carlezon WA, Wise RA (1996) Rewarding actions of phencyclidine and related drugs in nucleus accumbens shell and frontal cortex. $\mathrm{J}$ Neurosci 16:3112-3122.

Carlezon WA, Haile CN, Coppersmith R, Hayashi Y, Malinow R, Neve RL, Nestler EJ (2000) Distinct sites of opiate reward and aversion within the midbrain identified using a herpes simplex virus vector expressing GluR1. J Neurosci 20:RC62:1-5.

Churchill L, Kalivas PW (1992) Dopamine depletion produces augmented behavioral responses to a $\mu$-, but not a $\delta$-opioid, agonist in the nucleus accumbens: lack of a role for receptor upregulation. Synapse 11:47-57.

Churchill L, Klitenick MA, Kalivas PW (1998) Dopamine depletion reorganizes projections from the nucleus accumbens and ventral pallidum that mediate opioid-induced motor activity. J Neurosci 18:8074-8085

Cooper SJ, Turkish S (1989) Effects of naltrexone on food preference and concurrent behavioral responses in food deprived rats. Pharmacol Biochem Behav 33:17-20.

Corrigall WA, Coen KM (1991) Opiate antagonists reduce cocaine but not nicotine self-administration. Psychopharmacology 104:167-170.

Devine DP, Wise RA (1994) Self-administration of morphine, DAMGO, and DPDPE into the ventral tegmental area of rats. J Neurosci 14:1978-1984.

Glickman SE, Schiff BB (1967) A biological theory of reinforcement. Psychological Rev 74:81-109.

Goeders NE, Lane JD, Smith JE (1984) Self-administration of methionine enkephalin into the nucleus accumbens. Pharmacol Biochem Behav 20:451-455.

Hoffman AF, Lupica CR (2001) Direct actions of cannabinoids on synaptic transmission in the nucleus accumbens: a comparison with opioids. J Neurophysiol 85:72-83.

Ikemoto S, Panksepp J (1999) The role of nucleus accumbens dopamine in motivated behavior: a unifying interpretation with special reference to reward-seeking. Brain Res Brain Res Rev 31:6-41.

Ikemoto S, Sharpe LG (2001) A head-attachable device for injecting nanoliter volumes of drug solutions into brain sites of freely moving rats. J Neurosci Methods 110:135-140.

Ikemoto S, Murphy JM, McBride WJ (1997) Self-infusion of GABA antagonists directly into the ventral tegmental area and adjacent regions. Behav Neurosci 111:369-380.

Ikemoto S, Murphy JM, McBride WJ (1998) Regional differences within the rat ventral tegmental area for muscimol self-infusions. Pharmacol Biochem Behav 61:87-92.

Jenck F, Gratton A, Wise RA (1987) Opioid receptor subtypes associated with ventral tegmental facilitation of lateral hypothalamic brain stimulation reward. Brain Res 423:34-38.

Johnson K, Churchill L, Klitenick MA, Hooks MS, Kalivas PW (1996) Involvement of the ventral tegmental area in locomotion elicited from the nucleus accumbens or ventral pallidum. J Pharmacol Exp Ther 277:1122-1131.

Johnson SW, North RA (1992) Opioids excite dopamine neurons by hyperpolarization of local interneurons. J Neurosci 12:483-488.

Kalivas PW, Widerlov E, Stanley D, Breese G, Prange AJ (1983) Enkephalin action on the mesolimbic system: a dopamine-dependent and a dopamine-independent increase in locomotor activity. J Pharmacol Exp Ther 227:229-237.

Kirkham TC, Cooper SJ (1988) Naloxone attenuation of sham feeding is modified by manipulation of sucrose concentration. Physiol Behav 44:491-494.
Mansour A, Fox CA, Akil H, Watson SJ (1995) Immunohistochemical localization of the cloned mu opioid receptor in the rat CNS. J Chem Neuroanat 8:283-305.

Martin-Schild S, Gerall AA, Kastin AJ, Zadina JE (1999) Differential distribution of endomorphin 1- and endomorphin 2-like immunoreactivities in the CNS of the rodent. J Comp Neurol 405:450-471.

Nader K, van der Kooy D (1997) Deprivation state switches the neurobiological substrates mediating opiate reward in the ventral tegmental area. J Neurosci 17:383-390.

Navarro M, Carrera MR, Fratta W, Valverde O, Cossu G, Fattore L Chowen JA, Gomez R, del Arco I, Villanua MA, Maldonado R, Koob GF, de Fonseca FR (2001) Functional interaction between opioid and cannabinoid receptors in drug self-administration. J Neurosci 21:5344-5350.

Negus SS, Henriksen SJ, Mattox A, Pasternak GW, Portoghese PS, Takemori AE, Weinger MB, Koob GF (1993) Effect of antagonists selective for mu, delta and kappa opioid receptors on the reinforcing effects of heroin in rats. J Pharmacol Exp Ther 265:1245-1252.

Olds ME (1982) Reinforcing effects of morphine in the nucleus accumbens. Brain Res 237:429-440.

Olmstead MC, Franklin KB (1997) The development of a conditioned place preference to morphine: effects of microinjections into various CNS sites. Behav Neurosci 111:1324-1334.

Paxinos G, Watson C (1998) The rat brain in stereotaxic coordinates, Ed 4. New York: Academic.

Peter A, Toth G, Tomboly C, Laus G, Tourwe D (1999) Liquid chromatographic study of the enzymatic degradation of endomorphins, with identification by electrospray ionization mass spectrometry. J Chromatogr A 846:39-48.

Piepponen TP, Kivastik T, Katajamaki J, Zharkovsky A, Ahtee L (1997) Involvement of opioid mu 1 receptors in morphine-induced conditioned place preference in rats. Pharmacol Biochem Behav 58:275-279.

Schildein S, Agmo A, Huston JP, Schwarting RK (1998) Intraaccumbens injections of substance $\mathrm{P}$, morphine and amphetamine: effects on conditioned place preference and behavioral activity. Brain Res 790:185-194.

Sinclair JD (2001) Evidence about the use of naltrexone and for different ways of using it in the treatment of alcoholism. Alcohol Alcohol 36:2-10.

Stinus L, Winnock M, Kelley AE (1985) Chronic neuroleptic treatment and mesolimbic dopamine denervation induce behavioural supersensitivity to opiates. Psychopharmacology 85:323-328.

van der Kooy D (1987) Place conditioning: a simple and effective method for assessing the motivational properties of drugs. In: Methods for assessing the reinforcing properties of abused drugs (Bozarth MA, ed), pp 229-240. New York: Springer.

Welzl H, Kuhn G, Huston JP (1989) Self-administration of small amounts of morphine through glass micropipettes into the ventral tegmental area of the rat. Neuropharmacology 28:1017-1023.

Wilson AM, Soignier RD, Zadina JE, Kastin AJ, Nores WL, Olson RD, Olson GA (2000) Dissociation of analgesic and rewarding effects of endomorphin-1 in rats. Peptides 21:1871-1874.

Wise RA (1989) Opiate reward: sites and substrates. Neurosci Biobehav Rev 13:129-133.

Wise RA (1996) Neurobiology of addiction. Curr Opin Neurobiol 6:243-251.

Wise RA, Bozarth MA (1987) A psychomotor stimulant theory of addiction. Psychol Rev 94:469-492.

Wise RA, Spindler J, De Wit H, Gerber GJ (1978) Neuroleptic-induced "anhedonia" in rats: pimozide blocks the reward quality of food. Science 201:262-264.

Zadina JE, Hackler L, Ge LJ, Kastin AJA (1997) Potent and selective endogenous agonist for the mu-opiate receptor. Nature 386:499-502. 